\title{
A solidão entre idosos institucionalizados e 0 efeito do atendimento de fisioterapia
}

\author{
Nuno de Noronha da Costa Bispo*, Ruth Gelehrter da Costa Lopes*
}

\section{Resumo}

Numa instituição asilar, embora o idoso esteja rodeado de uma multidão, sente-se sozinho, uma vez que as pessoas marcantes na sua vida estão ausentes. A fisioterapia pode the proporcionar alívio, entendendo o idoso como um indivíduo biopsicossocial no seu ambiente. O objetivo deste estudo foi verificar o efeito do atendimento de fisioterapia em idosos institucionalizados que sofrem de solidão, em pesquisa qualitativa realizada no Asilo São Vicente de Paulo de Londrina - PR. Foram selecionadas seis pessoas com mais de 65 anos, atendidas pelos estagiários de Fisioterapia da Unopar. Para a coleta de dados utilizouse o método da entrevista não estruturada e, para a análise, a técnica hermenêutico-dialética. Os dados apresentados derivam de um dos dezoito significados da dissertação "O significado de um estágio de fisioterapia numa instituição de longa permanência para idosos". As atividades realizadas no atendimento mais relatadas pelos idosos foram a caminhada, o movimento, massagens e conversas. $\mathrm{O}$ alívio da solidão foi expresso de várias maneiras: a diminuição da tristeza, a humanização através dos cuidados e a atenção dispen- sada pelos alunos, a companhia para compartilhar um momento e transformar o dia e o desabafo para libertar algo que estava preso dentro de si. O movimento, o contato físico e as palavras têm um grande poder de "tocar" o emocional, através do afeto e do calor humano transferidos pelos alunos, significando para os idosos o alívio da solidão.

Palavras-chave: Fisioterapia. Idosos. Solidão.

\section{Introdução}

A institucionalização pode ser considerada uma modalidade de experiência denominada por Martins (2007) de "evento", na qual ocorrem mudanças ou transformações na vida do idoso. Essa experiência “caracteriza-se, não por dotar o sujeito de um maior saber, mas por abrir o sujeito à possibilidade como 'obrigação' de compreender-se a partir do que lhe sucede". O autor apresenta a definição de evento nas palavras do

* Professor do curso de Fisioterapia da Universidade Norte do Paraná. Mestre em Gerontologia pela Pontifícia Universidade Católica de São Paulo. Endereço para correspondência: Rua Fermino Barboza, 148, casa 9, bairro Aurora, CEP: 86.047-480, Londrina - PR. E-mail: nunofisio@hotmail.com.

** Professora e vice-coordenadora do Programa de Estudos Pós-Graduados em Gerontologia da Pontifícia Universidade Católica de São Paulo. Doutora em Saúde Pública pela Universidade de São Paulo.

$\rightarrow$ Recebido em maio de 2009 - Avaliado em março de 2010.

$\rightarrow$ doi:10.5335/rbceh.2010.008 
filósofo Claude Romano (apud MARTINS, 2007, p. 175): "O evento consiste na reconfiguração impessoal das minhas possibilidades e do mundo, que sobrevém com um fato e que institui uma fratura na minha aventura. Uma transformação de mim mesmo e do mundo, indissociável da experiência que faço dela."

O Asilo São Vicente de Paulo, localizado na zona sul da cidade, apresenta um espaço físico amplo, constituído por duas alas no formato retangular e em cuja volta se destacam jardins e arvoredo. Logo à entrada situa-se a ala um e, atrás dela, a dois ou enfermaria, as quais, juntas, abrigam atualmente aproximadamente cem idosos.

Os idosos da ala um são mais independentes e interagem mais, embora tenham a sensação de estar sós. Algumas mulheres ajudam no asilo e fazem crochê, podendo estar em companhia das amigas internas ou sozinhas; já os homens jogam bilhar, cartas e também ajudam no asilo. Há idosos que têm interesse em sair da instituição e deslocamse para algum lugar no bairro ou até mesmo ao centro da cidade, para passear ou tratar de assuntos pessoais.

$\mathrm{Na}$ ala dois os idosos têm mais dificuldade para realizar as atividades funcionais, apresentando maior dependência, o que os impede de participar dos acontecimentos ou atividades ocorridos durante o ano. Dificilmente os internos da enfermaria saem deste local, poucos se deslocam até a ala um. Alguns costumam frequentar o jardim, mas a maioria, em virtude das limitações físicas, circula pela enfermaria, tanto na área interna como na externa. São aqueles que utili- zam o movimento para realizar o essencial, ou pouco mais, como as atividades da vida diária, estar sentado num banco a fumar, olhar algum acontecimento (alguém a passar, um carro a estacionar, etc.). Assim passam o dia.

Os idosos cadeirantes, com dependência mais grave, permanecem num refeitório existente nos dois setores desta ala. A interação destes idosos é dificultada pela disposição das cadeiras de rodas ou poltronas, localizadas junto à parede, lado a lado ou de frente para aqueles que estão junto à outra parede, mais longe. Além desse aspecto, as incapacidades dificultam a interação social, favorecendo um estado estacionário de poucos movimentos e olhares fixos, que só se movem quando acontece algum evento neste ambiente. "Tudo se torna monótono, ou surpreendentemente vago e irregular, desencontrado". (PEREIRA, 2004, p. 73). Molino e Gil (1994, p. 371) descrevem essa situação com a seguinte frase: "os indivíduos calados eternamente numa sala à espera de um trem que nunca chega".

Mergulhados no seu mundo, no seu solilóquio - denominação dada por Ricoeur (2000, p. 26-27) ao "discurso solitário ou diálogo consigo mesmo" -, só se movimentam quando alguém inicia uma conversa. Então, desatam a referir-se ao passado, neste momento aproveitando o contato para falar tudo o que não falaram durante o dia. Às vezes são conversas em que se entende bem a pessoa; outras vezes, não têm nexo, existindo uma dificuldade de se expressar, principalmente se apresentarem algum défice sensorial ou cognitivo. 
Uma pessoa isolada há muito tempo pode ou tornar-se apática e ter dificuldade em estabelecer relações inter-pessoais e responder a perguntas, ou manifestar uma grande volubilidade de tal forma que se torna difícil estabelecer com ela uma conversa lógica e seguida. (BERGER, 1995, p. 404).

As características das duas alas são diferentes, dando a impressão de existirem dois asilos. Numa, apesar da solidão, existem momentos de alegria, mais participação e movimento, ao passo que na outra impera a conformação, indignação e dificilmente se notará qualquer expressão de ânimo. Alguns, para esquecer, tentam participar de todas as atividades que a instituição oferece; outros se movimentam para realizar afazeres indispensáveis, e ainda há aqueles cujo desinteresse pela vida é tamanho que chegam ao ponto de se entregar à inação.

Um dos problemas neste âmbito, que pode influenciar o movimento, está relacionado com o isolamento, sendo uma das causas da solidão. Conforme Vargas (1997), "o isolamento refere-se à falta de contatos com pessoas diferentes decorrente da ausência de atividades sociais". Martin-du-Pan et al. (1989, p. 440) também se referem ao isolamento como "o maior causador da solidão, noção mais difícil de definir, feita de uma carência dolorosa devido à falta de contatos profundos, ao sentimento de não contar para ninguém".

A solidão é uma das sensações que assombram quem mora em instituições. Embora o idoso esteja rodeado de outras pessoas, o sentimento de estar sozinho está presente, visto que as pessoas marcantes na sua vida estão ausentes. Vargas (1997) define solidão "como um estado emocional marcado pela carência de relacionamentos afetivos importantes e calorosos". Tais relacionamentos podem ser a ausência de familiares ou de outras pessoas mais próximas, como relatam Martin-du-Pan et al. (1989, p. 443) nas suas pesquisas: "As circunstâncias da vida jogam um papel decisivo na falta de contatos familiares. Entre os isolados, muitos perderam o cônjuge; os pais e os amigos envelheceram e também desapareceram". Na opinião de Berger (1995, p. 387), essa sensação é uma experiência demasiadamente árdua, determinada por relações sociais consideradas como insuficientes ou não satisfatórias.

Uma idosa internada no asilo com diagnóstico de depressão, que diariamente era atendida pela fisioterapia, passava as suas horas numa cadeira de rodas no refeitório, com fácies apática, braços cruzados e debruçada sobre si numa adinamia. Todos os dias havia dificuldade para que ela realizasse a deambulação, mas, mesmo motivando-a, poucas vezes deu alguns passos. O único procedimento de que ela gostava era ser massageada na região do músculo trapézio, quando dizia: "Aaah, isso sim é bom". Contudo, quando o filho a visitava, seu tronco se desenrolava, a postura melhorava, a apatia transformava-se em sorriso e alegria, os olhos se abriam e o azul da íris brilhava, os braços se apartavam e se movimentavam e, por incrível que pareça, acontecia o inesperado: ela começava a andar.

Se o filho marcava a ida ao asilo, logo de manhã começava a espera; apreensiva e ansiosa, penteada e perfumada, arrumada com o vestido mais novo e 
mais bonito que ela própria escolhera, sempre a olhar para a porta, ela esperava, esperava e esperava. Almejava vê-lo a qualquer momento. Nesses dias não fazia fisioterapia nem qualquer outra atividade que a tirasse daquele lugar, com receio de que o filho chegasse, não a visse e fosse embora. No final da tarde, aquela toda aquela expectativa se transformava em tristeza e desvanecimento, e ela voltava à sua posição habitual.

Segundo Comte-Sponville (2006, p. 125), o movimento é o ato propriamente dito, que depende da vontade ou potência de agir, mas, como se percebeu no caso relatado, a decepção pela ausência do filho transformava-se em desânimo, que inevitavelmente se tornava num fator forte de resistência ao movimento, vencendo a potência de agir.

As promessas de voltarem para casa ou de uma visita são fatores que aumentam a ansiedade e muitas vezes se transformam em frustração, porque ninguém aparece, nem para uma coisa nem para a outra. Berger (1995, p. 387) alude à solidão quando observa a fotografia de uma idosa sentada numa cadeira de rodas a olhar para a janela: "O tempo da velhice é longo quando passado à espera de algo ou de alguém."

Outra história foi aquela contada por Montagu, relatando sobre um bilhete encontrado num armário num asilo inglês, dirigido às enfermeiras. Era de uma senhora idosa que tinha falecido e estava intitulado: "Velha Ranzinza". Continha vários sentimentos de solidão, de fracasso da aceitação e do abandono vivenciados por muitos idosos, pois, numa "atitude cruel e insensível", muitos os consideram como que fazendo "hora extra”. (MONTAGU, 1988, p. 376).

Nessa perspectiva, nota-se a importância das relações intergeracionais, que são muito estimuladas na instituição, destacando-se a interação diária com os estagiários do curso de Fisioterapia da Universidade Norte do Paraná. Os diversos procedimentos que utilizam o toque, os movimentos, a atenção dispensada pelos alunos e o relacionamento com eles, a maneira de serem atendidos, os lugares escolhidos para o atendimento têm alguns significados, dentre os quais o alívio da solidão. Neste pensamento, esta pesquisa teve como objetivo verificar o efeito do atendimento de fisioterapia em idosos institucionalizados que sofrem de solidão.

\section{Metodologia}

\section{Tipo de pesquisa}

O presente trabalho constitui-se de uma pesquisa qualitativa e um estudo descritivo. Nesse sentido, segundo Bogdan (apud TRIVIÑOS, 1987, p. 128):

\begin{abstract}
A pesquisa qualitativa com apoio teórico na fenomenologia é essencialmente descritiva. E como as descrições estão impregnadas dos significados que o ambiente lhes outorga, e como aquelas, são produto de uma visão subjetiva, rejeita toda a expressão quantitativa, numérica, toda a medida. Desta maneira, a interpretação dos resultados surge como a totalidade de uma especulação que tem como base a percepção de um fenômeno num contexto.
\end{abstract}

O foco principal deste tipo de pesquisa "está no aprofundamento da compreensão de um fenômeno social por meio de 
entrevistas em profundidade e análises qualitativas da consciência articulada dos atores envolvidos no fenômeno". (RICHARDSON, 1999, p. 102).

\section{Universo e seleção}

A pesquisa realizou-se no Asilo São Vicente de Paulo em Londrina - PR, onde se desenvolve o estágio curricular de Fisioterapia pela Universidade Norte do Paraná. Durante seis semanas, um grupo de alunos atende os residentes desta instituição. Após esse período, outro grupo retoma as atividades, favorecendo uma troca contínua no processo aprendizado/assistência, interrompido somente no período de férias.

Foram selecionadas seis pessoas com 65 anos ou mais, lúcidas (cognição preservada), que residem na instituição e são usuárias dos serviços fornecidos pela fisioterapia ou não. Para não identificar os participantes do estudo, seu nome foi substituído e codificado pela letra "E" (de entrevistado) e por um número, pela ordem da entrevista. Desse modo, os participantes serão identificados como E1, E2, E3, até E21. As pessoas citadas na fala dos entrevistados foram trocadas por pseudônimos.

A pesquisa realizada na instituição deu a oportunidade de se conseguir não só uma aproximação com aquilo que desejamos conhecer e estudar, mas também desenvolver conhecimento, partindo da realidade presente no local investigado. (MINAYO, 2007). Nessa perspectiva, Pope e Mays (2006) indicam a necessidade de se estudarem as pessoas em seu ambiente natural, não em ambientes artificiais ou experimentais.

\section{Materiais e métodos}

Neste estudo utilizou-se a técnica da entrevista, maneira pelo qual o pesquisador colhe informações intencionalmente num trabalho de campo, e empregou-se a entrevista não-estruturada, durante a qual o indivíduo expõe livremente sobre $o$ assunto referido. (MINAYO, 2007). A autora acrescenta que este tipo de entrevista favorece o diálogo entre o pesquisador e o entrevistado, e o simbolismo expressado pelas palavras pode apresentar vários significados, caracterizando a polissemia.

No entanto, o contexto do diálogo tem a função de "filtrar a polissemia das palavras e reduzir a pluralidade das interpretações possíveis", evitando o entendimento impróprio da fala dos indivíduos. (RICOUER, 2000, p. 28). O autor considera que o diálogo é um modo de comunicar e expressar a experiência, possibilitando uma troca intersubjetiva e permitindo ao ser humano superar a "solidão", não aquela causada pelo isolamento, mas o fato de poder transferir a significação da experiência, que é única de cada indivíduo.

Para Tuan (1983, p. 10), "experienciar é aprender; significa atuar sobre o dado e criar a partir dele. $\mathrm{O}$ dado não pode ser conhecido em sua essência. $\mathrm{O}$ que pode ser conhecido é uma realidade que é um constructo da experiência, uma criação do sentimento e pensamento". O autor completa o seu raciocínio destacando que "experiência implica a capacidade de aprender a partir da própria vivência”. 
Debert (2004, p. 99) inicia um dos capítulos do seu livro A reinvenção da velhice com uma observação interessante: "Pesquisar a velhice em asilos é frequentemente uma tentativa de aproximação de uma experiência que compreende, pelo menos, duas facetas distintas". Aqui a autora refere-se às imagens negativas, representadas pelo aspecto comovente da solidão, e às positivas, nas quais o idoso é visto como sábio, como indivíduo com experiência acumulada, entre outras qualidades.

O atendimento dos estagiários está sob o "olhar" dos idosos, ou seja, o somatório das sensações será a percepção desta vivência, que resultará em variados significados comuns e distintos para os idosos. Para esclarecer alguns aspectos importantes da pesquisa utilizaram-se as seis categorias da classificação de Lofland (apud TRIVIÑOS, 1987, p. 127), enumeradas abaixo:

1 os atos: são as ações ou procedimentos aprendidos durante o curso, realizados pelos estagiários no atendimento aos idosos;

2 as atividades: esses procedimentos estão baseados na ideia do idoso como um ser biopsicossocial;

3 os significados: aão as produções verbais dos idosos que experienciam a presença dos estagiários de Fisioterapia. Uns recebem o atendimento, outros simplesmente observam esse atendimento;

4 a participação: é o envolvimento dos idosos que participam do estudo;

5 as relações: são as conexões entre alunoidoso, ou seja, as ligações intergeracionais;

6 as situações: compreende o "foco do estudo", que neste caso é o objetivo da pesquisa.

Os dados subjetivos, definidos como as opiniões dos sujeitos por Cruz Neto
(2003, p. 58), foram registrados em gravação num aparelho $\mathrm{mp} 4$, sendo posteriormente transcritos, com a descrição exata da fala dos indivíduos como foi transmitida e, inclusive, retrataando ruídos e gestos, como sugere Myers (2004, p. 275). Quando o diálogo é passado para a forma escrita, são inseridas "as marcas linguísticas da enunciação oral”, mas também os fatos não linguísticos, como expressões fisionômicas e gestuais, simbolizadas por citações, pontos de exclamação e de interrogação. (RICOEUR, 2000, p. 29). O autor indica a importância da escrita, porque referencia o homem no mundo.

Todo esse procedimento administrativo para a realização da pesquisa foi submetido à autorização da instituição, porém, do ponto de vista acadêmico, o projeto não foi submetido ao Comitê de Ética em Pesquisa da universidade, ainda que o termo de consentimento livre e esclarecido fosse assinado em duas vias pelos sujeitos entrevistados.

\section{Análise dos dados}

Nesta pesquisa, utilizou-se o método hermenêutico-dialético, caracterizado pelo entendimento de uma fala ou de um depoimento proposto por Minayo. Nesse aspecto, este tipo de análise é o mais indicado e com maior capacidade para dar uma "interpretação aproximada da realidade". (MINAYO, 2007, p. 231). Segundo a proposta da autora, seguiramse os seguintes passos:

a) ordenação dos dados: esta fase compreendeu o mapeamento de todos os dados obtidos pela entre- 
vista, que incluem a transcrição das gravações, a releitura dos textos e a organização dos relatos numa determinada ordem;

b) classificação dos dados: neste momento os dados foram embasados com a fundamentação teórica. Esta fase pode ser dividida em duas etapas: a primeira consistiu numa "leitura flutuante", constituída por leitura extenuante, minuciosa e redobrada das transcrições para compreender as ideias centrais que transmitem os pontos-chave do tema do trabalho. $\mathrm{Na}$ segunda etapa foi feita uma "leitura transversal" de cada texto transcrito e realizado o "recorte de cada entrevista" em uma "unidade de registro" e, em seguida, referenciada por assunto. Depois disso, operou-se uma seleção dos temas mais relevantes que evidenciaram as hipóteses do trabalho;

c) análise final: nesta fase, apresentaram-se as falas dos entrevistados mais significativas e $o$ referencial teórico, respondendo às questões da pesquisa com base nos objetivos.

\section{Resultados}

$\mathrm{O}$ toque massageia suavemente os sentimentos de angústia do idoso, confortando e aliviando o sofrimento. Nas falas dos entrevistados entende-se o toque como um sinal de afeto, transmitido de várias maneiras: pelo contato físico, pelo olhar, pelo diálogo - onde se fala e se escuta. Neste pensamento, apesar de estarem rodeados de pessoas, os idosos sentem-se sós; contudo, essa sensação é rompida com a atuação dos estagiários, segundo os relatos dos entrevistados:

"É ruim quando termina, fico parada sentada, sozinha lá no meu canto. Tenho amigas, mas elas conversam pouco, os alunos de fisioterapia conversam mais." (E1)

"Eu acho bom, a gente se distrai um pouco, faz caminhada [...]. Às vezes a gente não está a fim de andar, aí ele vem, dá aquela força, daí a gente sai para caminhar, se distrai, conversa [...], vê outras pessoas. Penso numa coisa sentimental da minha vida, eu choro e desabafo. A gente vai conversando, lembro daquela mágoa, vai ver estou chorando [...], é uma pessoa que entende, aí costuma dar uma força para a gente. Assim, desabafo e me sinto bem." (E2)

"Caminhada eu gosto de fazer, mas não tenho companhia. A gente vive muito sozinha [...], e ter uma pessoa para ajudar a gente, a gente gosta. A gente precisa muito de terapia, porque a gente vive muito sozinha $\mathrm{e}$ gosta de estar com o pessoal." (E3)

"Me sentia bem, caminhava, conversava. Vivo muito na solidão, fico sem falar com ninguém, [...]. Conversava da casa, do namorado dela, também falava do cachorrinho dela. Uma vez colocou uma luz aqui atrás, onde me doía. Acho bom, porque eu acho que a gente se distrai, tira as coisas da cabeça, a tristeza, porque a gente vive na solidão. Eu também sofro de solidão, dá vontade de chorar muitas vezes." (E4)

"É importante porque a pessoa pra começar tem um amigo ou uma amiga, pra andar, pra dar umas caminhadas e fazer ginástica [...]. Eu gosto é de ter amizade com todo o mundo." (E5)

"Eu gosto de estar no meio do pessoal, dos meus colegas, das minhas amigas e de vocês. Fico meio triste porque eu gosto de ficar no meio do pessoal igual eu tava. Como a gente está aqui, conversando, a gente identifica muita coisa. [...] a amizade com todos, com 
vocês aí, qualquer coisa vocês estão passando, agente fica alegre. Graças a Deus vocês estando aí, agente está animoso, agente fica mais alegre. Quando vocês saem, agente fica triste." (E6)

\section{Discussão}

Durante o atendimento, o estagiário de Fisioterapia utiliza o toque para a realização dos exercícios, transmitindo muito mais que simples movimento. $\mathrm{O}$ "envolvimento emocional do tato" é um meio de se aproximar do "isolado ancião e comunicar-lhe amor, confiança, afeto e calor humano"; uma vez que se apresenta desamparado e vulnerável em razão de suas deficiências. (MONTAGU, 1988, p. 372).

Nas falas dos entrevistados, nota-se a importância do diálogo, que geralmente acontecia durante a caminhada. A fala é a forma de o indivíduo transmitir a significação de suas experiências e sentimentos (RICOUER, 2000), e a escuta, um modo de compartilhar (BARTHES apud PONZIO, 2007, p. 275), “[...] é estar aberto existencialmente da presença, enquanto ser-com os outros", "[...] o ouvir possui o modo de ser de uma escuta compreensiva”. (HEIDEGGER, 2006, p. 226).

Também está demonstrado nas falas dos entrevistados que os alunos souberam compartilhar o momento do diálogo, dando espaço para o idoso desabafar, libertando algo que incomodava, angustiava e estava preso dentro de si. Às vezes o aluno não se apercebe que um pequeno gesto tem o poder de transformar o dia dessas pessoas. Afora a fala e a escuta, o silêncio é outro elemento que constitui o diálogo; é a forma de compreender "aquele que não perde a palavra” (HEIDEGGER, 2006, p. 228) e transformar o que se ouve numa escuta lógica, não passiva. (FOUCAULT, 2006, p. 410). Nisso o autor também afirma a importância de se adotar o silêncio e não interromper quem fala. Estar atento para assimilar o que é falado e evitar atitudes físicas, como a agitação, para não interferir na escuta.

$\mathrm{Na}$ área da saúde o diálogo não pertence apenas ao início do tratamento, quando o fisioterapeuta realiza a anamnese, mas faz parte do próprio tratamento, direcionando à cura (GADAMER, 2006, p. 133). Para ter esse efeito, o de participar da cura, tanto a fala como a escuta são de forma útil, ou seja, a fala com destreza ou "arte" e a escuta, com experiência, competência, prática, atenção, entre outras. (FOUCAULT, 2006, p. 408).

Referindo-se ao olhar, Claude Gandelman (apud PONZIO, 2007, p. 267) afirma que "[...] o olho é uma criatura táctil, um agente de contato humano. Em virtude do seu simples toque o olho dá vida".

Todas as sensações descritas têm grande importância para estimular os relacionamentos do idoso. Reforça Zimerman (2000, p. 136) em suas palavras esta ideia de que "o contato com outras pessoas, ver, falar, comunicar-se, trocar afeto, [...] cria novas condições de vida. É o calor humano, aquele abraço, aquele papo, fazendo a pessoa viver mais e em melhores condições".

"Juntos" é a palavra que ComteSponville (2007) indica que ninguém pode viver só. Cada pessoa depende de outras vidas humanas; afinal, vive-se 
em comunidade. E é o que alguns idosos sentem no asilo, onde estão rodeados de pessoas, mas sentem-se sós.

\section{Considerações finais}

Frequentemente, os alunos relatam o desânimo dos idosos para realizar o atendimento planejado, pois nem sempre eles estão com a mesma aptidão todos os dias. Entretanto, já foram surpreendidos muitas vezes com as mudanças ocorridas nesses entrevistados. Simplesmente algumas palavras, um olhar, o escutar, o toque e o movimento podem provocar efeitos benéficos no estado de saúde das pessoas. O fisioterapeuta pode lançar mão desses recursos, sejam isolados, sejam associados, para conseguir resultados satisfatórios. Às vezes nem se imagina que um simples ato assuma significados espantosos, como pudemos conferir na pesquisa.

Loneliness among institutionalized elderly people and the effect of physiotherapy

\section{Abstract}

Although the elderly is surrounded by many people in nursing homes, they feel lonely, since those who played an important role in their lives are absent. Physiotherapy can provide some relief by looking at the elderly as a biopsychosocial being in his/her environment. To verify the effect of Physiotherapy on institutionalized elderly people who suffer from loneliness.: Qualitative research conducted at the São Vicente de Paulo Nursing Home in Londrina/PR. Participated in the research 06 people over 65, who were seen by Physiotherapy Interns at Universidade do Paraná (Unopar). Data were collected through non-structured interviews and analyzed by the hermeneutics-dialectics technique. Findings were based on one of the eighteen significances introduced in the dissertation "The significance of a physiotherapy internship in a long-stay nursing home". Among the most cited activities by the elderly were walks, movement, massages and conversations. Loneliness relief was expressed in several ways: reduced sadness, humanization through the care and attention given by the students, companionship to share a moment and change the day, and a moment to vent something that was kept inside. The movement, physical contact and words have great power to "touch" the emotional through the affection and human warmth transferred by the students, thus relieving the elderly from their loneliness.

Key words: Physiotherapy. Elderly. Loneliness.

\section{Referências}

BERGER, L. Evitar os perigos. In: BERGER, L.; MAILLOUX-POIRIER, D. Pessoas idosas. Lisboa: Lusodidacta, 1995. p. 379-438.

COMTE-SPONVILLE, A. A vida humana. São Paulo: Martins Fontes, 2007.

O amor a solidão. 2. ed. São Paulo: Martins Fontes, 2006.

CRUZ NETO, O. O trabalho de campo como descoberta e criação. In: MINAYO, M. C. S. (Org.). Pesquisa social: teoria, método e criatividade. 22. ed. Petrópolis: Vozes, 2003. p. 51-66.

DEBERT, G. G. A reinvenção da velhice. São Paulo: Edusp, 2004.

FOUCAULT, M. A hermenêutica do sujeito. 2. ed. São Paulo: Martins Fontes, 2006.

GADAMER, H.-G. O caráter oculto da saúde. Petrópolis: Vozes, 2006.

HEIDEGGER, M. Ser e tempo. Petrópolis: Vozes: Edusf, 2006. 
MARTIN-DU-PAN, R. et al. Les caractéristiques des personnes très isolées. Schweiz. Rundschau Med., v. 8, n. 15, p. 440-444, 1989.

MARTINS, J. G. Experiência e subjetividade em Claude Romano. In: CANTISTA, M. J. (Org.). Desenvolvimento da fenomenologia na contemporaneidade. Porto: Campo das Letras, 2007. p. 167-214.

MINAYO, M. C. S. O desafio do conhecimento: pesquisa qualitativa em saúde. 10. ed. São Paulo: Hubitec/Abrasco, 2007.

MOLINO, J. P.; GIL, E. A. Cuidados del paciente com demência. In: LLERA, F. G.; MARTIN, J. P. M. Síndromes y cuidados en el paciente geriátrico. Barcelona: Masson, 1994. p. 357-380.

MONTAGU, A. Tocar: o significado humano da pele. 9. ed. São Paulo: Summus, 1988.

MYERS, G. Análise da conversação e da fala. In: BAUER, M. W.;1 GASKELL, G. Pesquisa qualitativa com texto, imagem e som: um manual prático. 3. ed. Petrópolis: Vozes, p. 271-292. 2004.

PEREIRA, M. O tempo de vida e a vivência do tempo. In: QUARESMA, M. L. (Org.) et al. O sentido das idades da vida: interrogar a solidão e a dependência. Lisboa: CESDET, 2004. p. 73-81.

PONZIO, A.; CALEFATO, P.; PETRILLI, S. Fundamentos de filosofia da linguagem. Petrópolis: Vozes, 2007.

POPE, C.; MAYS, N. Pesquisa qualitativa na atenção à saúde. 2. ed. São Paulo: Artmed, 2006.

RICHARDSON, R. J. Pesquisa social: métodos e técnicas. 3. ed. São Paulo: Atlas, 1999.

RICOEUR, P. Teoria da interpretação. Lisboa: Edições 70, 2000.

VARGAS, H. S. A sociologia do envelhecimento. In: UNIVERSIDADE DO ESTADO DO RIO DE JANEIRO. Universidade Aberta da Terceira Idade: $2^{\circ}$ Curso de Formação de Cuidadores de Idosos Dependentes. Rio de Janeiro, UERJ, 1997. p. 6-12
TRIVIÑOS, A. N. S. Pesquisa qualitativa. In: TRIVIÑOS, A. N. S. Introdução à pesquisa em ciências sociais: a pesquisa qualitativa em educação. São Paulo: Atlas, 1987. p. 116-175 TUAN, Y. F. Espaço e lugar. São Paulo: Difel, 1983.

ZIMERMAN, G. I. Velhice: aspectos biopsicossociais. Porto Alegre: Artmed, 2000. 